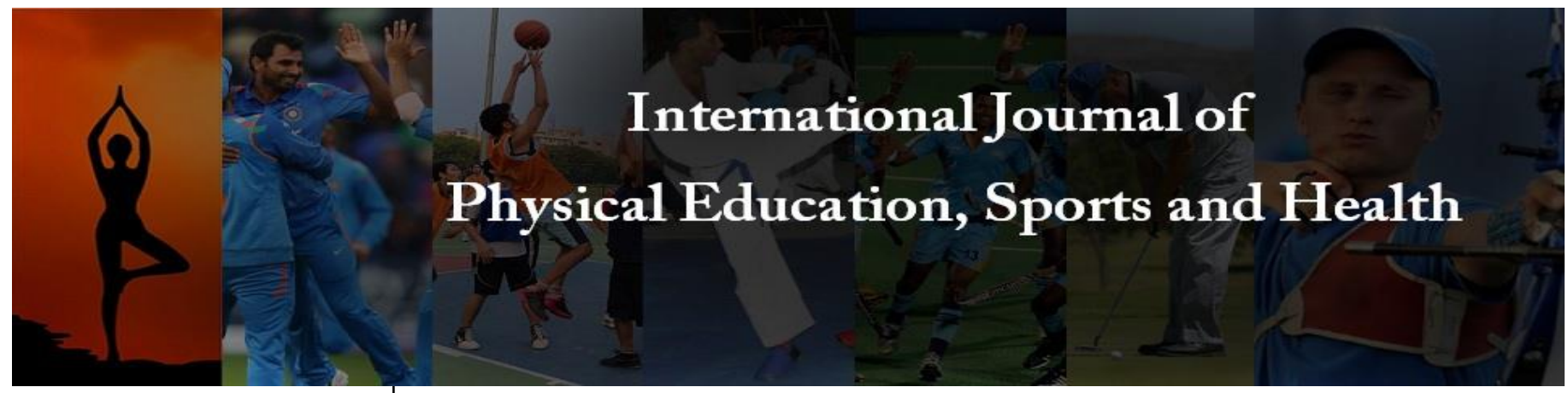

P-ISSN: 2394-1685

E-ISSN: 2394-1693

Impact Factor (ISRA): 5.38

IJPESH 2021; 8(3): 293-296

(C) 2021 IJPESH

www.kheljournal.com

Received: 14-03-2021

Accepted: 20-04-2021

Dr. S Chidambara Raja

Professor, Department of

Physical Education, Annamalai

University, Tamil Nadu, India
Corresponding Author: Dr. S Chidambara Raja Professor, Department of Physical Education, Annamalai University, Tamil Nadu, India

\section{Influence of resistance and endurance training and combination of resistance and endurance training on back strength flexibility and cardio-respiratory endurance}

\section{Dr. S Chidambara Raja}

DOI: $\underline{\text { https://doi.org/10.22271/kheljournal.2021.v8.i3e.2099 }}$

\section{Abstract}

The purpose of the study was to find out the effect of resistance training and combination of resistance and endurance training on back strength, flexibility and cardiorespiratory endurance. Sixty male students aged between 17 and 22 years studying in various faculties of Annamalai University were selected. They were divided into four equal groups, each group consisting of fifteen subjects, in which group I $(n=15)$ underwent resistance training, group II $(\mathrm{n}=15)$ underwent endurance training, group III $(\mathrm{n}=15)$ underwent combination of resistance and endurance training for three days (alternative days) per week for twelve weeks, and group IV ( $\mathrm{n}=15)$ acted as control, which did not participate in any training. The subjects were tested on selected criterion variables such as back strength, flexibility and cardiorespiratory endurance at prior to and immediately after the training period. For testing the back strength, the dynamometer was used, to test the flexibility, sit and reach test was administered, to measure cardiorespiratory endurance, Cooper's 12 minutes run/walk test was administered. The analysis of covariance (ANCOVA) was used to find out the significant difference if any, between the experimental groups and control group on selected criterion variables separately. Since three groups were involved in the present study, the Scheffé $S$ test was used as post-hoc test. The selected criterion variables such as back strength, flexibility and cardio-respiratory were improved significantly for all the training groups when compared with the control group and the back strength and flexibility were improved significantly for resistance training group and the endurance training group has improved cardiorespiratory endurance significantly.

Keywords: Resistance training, endurance training, combined training, back strength, flexibility and cardio-respiratory endurance

\section{Introduction}

Physical training is focuses on mechanistic goals. The overall muscles and some specific skill will develop within particular period of time after the physical training. Physical fitness will be improved by the most of the physical training programme ${ }^{[1]}$. Dale S. Beach ${ }^{[2]}$ defines training as 'the organized procedure by which people learn knowledge and/or skill for a definite purpose'. It is a process of teaching of particular skill to somebody, either human or animal and the aim is to improve the capacity, performance capacity or productivity of an individual ${ }^{[3]}$.

Physical training is the most important ingredient to achieve high level of performance of athlete. It's objectives are to increase the highest standards of an athletes' physiological potential and biomotor abilities ${ }^{[4]}$. Physical training should be given to the athlete on the basis of scientific principles and which, through systematic development of mental and physical efficiency, capacity and motivation, which help the athlete to produce outstanding and record breaking performances ${ }^{[5]}$.

During a specific period of time, an organized training which involves increasing cycle of training programme which enhance the performance of an individual is called as periodization [6]. During the periodization, the competitor gets optimum adaptation before an important event. Instead of performing the regular routing workouts month after month, the athlete change his or her program with regular periods or interval to work harder with adequate rest ${ }^{[7]}$. 
A study was conducted at Human Performance Laboratory, Ball State University shown that there was a significant difference was found in favour of periodized strength training programme than the non-periodized program ${ }^{[8]}$.

The resistance training also refers as a type of physical exercise, uses of resistance which enhance the muscular contraction which contributes the strength, increase the size of skeletal muscle and anaerobic endurance. It can improve the overall health and well-being, including the size of muscle, tendon, strengthen and improves the toughness of ligament and joint function, reduced for injury ${ }^{[9]}$ increased the bone density, fitness, metabolism and cardiac function ${ }^{[10,11]}$.

Training the aerobic system is called as endurance training which is opposed to the anaerobic system, which is divided into two categories, general and specific endurance ${ }^{[12]}$. Endurance fitness which sustain the necessary activity level for a specific competitive sport, which includes both cardiovascular and flexibility required for the sport ${ }^{[13]}$. In physiological aspect, it requires the circulatory and respiratory systems to supply energy to the working muscles to support sustained physical activity. Endurance requires the circulatory and respiratory systems to supply energy to the working muscles in order to support sustained physical activity ${ }^{[14]}$. Indeed, high levels of flexibility and aerobic endurance are key determinants of success in many sports ${ }^{[15,16]}$.

\section{Methods}

In this study it was aimed to find out the effect of resistance training and combination of resistance and endurance training on back strength, flexibility and cardio-respiratory endurance. To achieve the purpose sixty male students from various faculties of Annamalai University, Annamalainagar, Tamil Nadu were selected as subjects at random from the total population of 181 students. They were divided into four equal groups of fifteen each and further divided as two experimental groups and one control group, in which the group $I(n=15)$ underwent resistance training, group II $(\mathrm{n}=15)$ underwent endurance training, group III $(n=15)$ underwent combination of resistance and endurance training for three days (alternative days) per week for twelve weeks, and group IV $(\mathrm{n}=15)$ acted as control, which did not participate in any training apart from the regular curricular activities.

For every training programme there would be a change in various structure and systems in human body. So, the researchers consulted with the experts in training methods and then selected the following as criterion variables: 1. Back strength, 2. Flexibility and 3. Cardio-respiratory endurance.

\section{Analysis of the Data}

Analysis of covariance was used to determine the differences, if any, among the adjusted post test means on selected criterion variables separately. Whenever the ' $F$ ' ratio for adjusted post test mean was found to be significant, the Scheffé $S$ test was applied as post-hoc test. The level of significance was fixed at .05 level of confidence to test the ' $F$ ' ratio obtained by analysis of covariance.

Table 1: Analysis of Covariance and 'F' ratio for Back strength, Flexibility and Cardio-respiratory Endurance of Resistance training Group, Endurance Training Group Combined Training Group and Control Group

\begin{tabular}{|c|c|c|c|c|c|c|}
\hline Variable Name & Group Name & $\begin{array}{c}\text { Resistance training } \\
\text { Group }\end{array}$ & $\begin{array}{c}\text { Endurance Training } \\
\text { Group }\end{array}$ & $\begin{array}{c}\text { Combined Training } \\
\text { Group }\end{array}$ & Control Group & $\begin{array}{c}\text { 'F' } \\
\text { Ratio }\end{array}$ \\
\hline \multirow{3}{*}{ Back strength (in Kgs.) } & Pre-test Mean \pm S.D. & $38.46 \pm 1.0$ & $37.20 \pm 1.8$ & $38.19 \pm 1.2$ & $39.81 \pm 1.9$ & 1.098 \\
\hline & Post-test Mean \pm S.D. & $40.26 \pm 1.4$ & $38.55 \pm 1.5$ & $39.73 \pm 1.9$ & $38.53 \pm 1.6$ & $5.86 *$ \\
\hline & \begin{tabular}{|l|} 
Adj. Post-test Mean \\
\end{tabular} & 41.85 & 39.29 & 40.27 & 38.11 & $25.43^{*}$ \\
\hline \multirow{3}{*}{ Flexibility (in cm) } & \begin{tabular}{|l|} 
Pre-test Mean \pm S.D. \\
\end{tabular} & $12.86 \pm$ & $13.11 \pm 0.11$ & $12.33 \pm 0.81$ & $12.73 \pm 0.9$ & 0.993 \\
\hline & Post-test Mean \pm S.D. & $15.53 \pm 0.32$ & $14.87 \pm 0.86$ & $15.86 \pm 0.97$ & $12.31 \pm 0.86$ & $7.26 *$ \\
\hline & Adj. Post-test Mean & 16.76 & 15.61 & 16.95 & 12.45 & $31.61 *$ \\
\hline \multirow{3}{*}{$\begin{array}{c}\text { Cardio-respiratory } \\
\text { Endurance (in Meters) }\end{array}$} & Pre-test Mean \pm S.D. & $1086.31 \pm 122$ & $1067.51 \pm 236$ & $1079.86 \pm 183$ & $1081.36 \pm 154$ & 1.371 \\
\hline & Post-test Mean \pm S.D. & $1209.73 \pm 145$ & $1408.33 \pm 171$ & $1413.45 \pm 201$ & $1033.51 \pm 122$ & $12.33^{*}$ \\
\hline & t Mean & 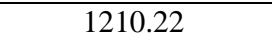 & 1433.8 & 1406.87 & 1054.23 & \\
\hline
\end{tabular}

* Significant at .05 level of confidence. (The table value required for significance at .05 level of confidence with df 3 and 56 and 3 and 55 were 2.77 and 2.78 respectively).

Table -1 shows that pre and post test means 'f' ratio of resistance training group, endurance training group, combined training group and control group on back strength was 1.098, which is insignificant at 0.05 level of confidence. The post and adjusted post test mean ' $\mathrm{f}$ ' ratio value of experimental groups and control group was 5.86 and 25.43 which was significant at 0.05 level of confidence. The pre test means ' $\mathrm{f}$ ' ratio of resistance training group, endurance training group, combined training group and control group on flexibility was 0.993, which is insignificant at 0.05 level of confidence. The post and adjusted post test mean ' $\mathrm{f}$ ' ratio value of experimental groups and control group was 7.26 and 31.61 , which was significant at 0.05 level of confidence. The pre test means ' $\mathrm{f}$ ' ratio of resistance training group, endurance training group, combined training group and control group on cardio-respiratory endurance were 1.371 which is insignificant at 0.05 level of confidence. The post test and adjusted post test mean ' $\mathrm{f}$ ' ratio value of experimental groups and control group were 12.33 and 38.63, which was significant at 0.05 level of confidence. The overall study shows that there was a significant increase in back strength, flexibility and cardio-respiratory endurance. Further, to find out which of the paired mean significantly differ, the Scheffe $S$ test was applied and presented below.

Table 2: Scheffẽ S Test for the Difference between the Adjusted Post-Test Mean of Back strength Flexibility and Cardio-respiratory Endurance

\begin{tabular}{|c|c|c|c|c|c|}
\hline \multicolumn{5}{|c|}{ Adjusted Post-test Mean for Back strength } \\
\hline $\begin{array}{c}\text { Resistance training } \\
\text { Group }\end{array}$ & $\begin{array}{c}\text { Endurance Training } \\
\text { Group }\end{array}$ & $\begin{array}{c}\text { Combined Training } \\
\text { Group }\end{array}$ & $\begin{array}{c}\text { Control } \\
\text { Group }\end{array}$ & $\begin{array}{c}\text { Mean } \\
\text { Difference }\end{array}$ & $\begin{array}{c}\text { Confidence Interval at 0.05 } \\
\text { level }\end{array}$ \\
\hline 41.85 & 39.29 & & & $2.56^{*}$ & 1.07 \\
\hline 41.85 & & 40.27 & & $1.58^{*}$ & 1.07 \\
\hline 41.85 & & & 38.11 & $3.74^{*}$ & 1.07 \\
\hline & 39.29 & 40.27 & & 0.98 & 1.07 \\
\hline
\end{tabular}




\begin{tabular}{|c|c|c|c|c|c|}
\hline & 39.29 & & 38.11 & $1.18^{*}$ & 1.07 \\
\hline & & 40.27 & 38.11 & $2.16 *$ & 1.07 \\
\hline \multicolumn{6}{|c|}{ Adjusted Post-test Mean for Flexibility } \\
\hline 16.76 & 15.61 & & & $1.15^{*}$ & 0.94 \\
\hline 16.76 & & 16.95 & & 0.19 & 0.94 \\
\hline \multirow[t]{4}{*}{16.76} & & & 12.45 & $4.31 *$ & 0.94 \\
\hline & 15.61 & 16.95 & & $1.34 *$ & 0.94 \\
\hline & 15.61 & & 12.45 & $3.16^{*}$ & 0.94 \\
\hline & & 16.95 & 12.45 & $4.50^{*}$ & 0.94 \\
\hline \multicolumn{6}{|c|}{ Adjusted Post-test Mean for Cardio-respiratory Endurance } \\
\hline 1210.22 & 1433.86 & & & $223.64 *$ & 28.18 \\
\hline 1210.22 & & 1406.87 & & $196.65 *$ & 28.18 \\
\hline \multirow{4}{*}{1210.22} & & & 1054.23 & $155.99 *$ & 28.18 \\
\hline & 1433.86 & 1406.87 & & 26.99 & 28.18 \\
\hline & 1433.86 & & 1054.23 & $379.99 *$ & 28.18 \\
\hline & & 1406.87 & 1054.23 & $352.64 *$ & 28.18 \\
\hline
\end{tabular}

* Significant at 0.05 level of confidence.

Table -2 shows that the Scheffe $S$ Test for the difference between adjusted post-test mean of resistance training group and endurance training groups (2.56), resistance training group and combined training group (1.58), resistance training group and control group (3.74), endurance training group and control group (1.18) and combined training group and control group (2.16), which were significant at 0.05 level of confidence. But there was no significant difference between endurance training group and combined training group (0.98) on back strength after the respective training programme.

Table - II also shows that the Scheffe $S$ Test for the difference between adjusted post-test mean difference in flexibility between resistance training group and endurance group (1.15), resistance training group and control group (4.31), endurance training group and combined training groups (1.34), endurance training group and control group (3.16), combined training group and control group (4.50) were significant at 0.05 level of confidence. But there was no significant difference between resistance training group and combined training group $(0.19)$ on flexibility after the training programme.

Table -2 shows that the Scheffe $S$ Test for the difference between adjusted post-test mean difference in cardiorespiratory endurance between resistance training group and endurance group (223.64), resistance training group and combined training group (196.65), resistance training group and control group (155.99), endurance training group and control group (379.99) combined training group and control group (352.64) were significant at 0.05 level of confidence. But there was no significant difference between endurance training group and combined training group (26.99) on cardio-respiratory endurance after the respective training programme.

\section{Conclusions}

The result of the present study shows that the back strength has improved all the training groups except, endurance training group. Findings of Yiannis et al. ${ }^{[17]}$ and Bartholomew et al. ${ }^{[18]}$ supports the results of the present study. Roelants, et al. ${ }^{[19]}$ found that there was a significant improvement in back strength after 24 weeks whole body vibration and standard fitness training programme (strength and cardio-vascular training). Hong et al. ${ }^{[20]}$ reported that, an improvement was found in flexibility and strength after the resistance training programme. Hickson ${ }^{[21]}$ reported that there was a significant improvement in $\mathrm{VO} 2$ max after the endurance training, but the strength gain was not improved when compared with the weight training group.

\section{Reference}

1. Retrieved from https://en.wikipedia.org/wiki/Training on 10-6-2019.

2. Retrieved from

http://www.yourarticlelibrary.com/human-resourcedevelopment/training-meaning-definition-and-types-oftraining/32374 on 10-06-2019.

3. What is training? Definition and examples, retrieved from https://marketbusinessnews.com/financialglossary/training/ on 11-06-2019

4. Tudor O Bompa, Buzzichelli CA. Periodization: Theory and Methodology of Training, (4 ${ }^{\text {th }}$ ed.,), (Champaign, Illinois: Human Kinetics Publishers, 1999), p.54.

5. Dietrich Harre. Principles of Sports Training, (Sportverlag, Berlin, 1982, p.10.

6. Retrieved from https://www.unm.edu/ lkravitz/Exercise\%20Phys/periodi zationexpl.html on 22-6-2019.

7. American Council of Exercise, Periodized training and why it is important?, retrieved from https://www.acefitness.org/education-andresources/lifestyle/blog/6660/periodized-training-andwhy-it-is-important on 18-06-2019.

8. Marx JO et al. Low volume circuit versus high-volume periodized resistantce training in women, Medicine \& Science in Sports \& Exercise 2001;33:635-643.

9. Shaw I, Shaw BS. Resistance training and the Prevention of Sports Injuries. In Hopkins G (ed). Sports Injuries: Prevention, Management and Risk Factors, (Hauppauge, NY: Nova Science Publishers), 2014. ISBN 9781634633055.

10. Shaw BS, Shaw I. Effect of resistance training on cardiorespiratory endurance and coronary artery disease risk, Cardiovascular Journal of South Africa 2005;16(5):256-59.

11. Shaw BS, Shaw I. Compatibility of concurrent aerobic and resistance training on maximal aerobic capacity in sedentary males, Cardiovascular Journal of Africa 2009;20(2):104-6.

12. Retrieved from https://en.wikipedia.org/wiki/Endurance_training\#cite_no te-1 on 10-6-2019.

13. Retrieved from https://www.sports-trainingadviser.com/endurancefitness.html on 14-6-2019.

14. Retrieved https://www.busywomensfitness.com/exercisebenefits.html on 9-3-2016.

15. Baar K. Using molecular biology to maximize concurrent 

10.1007/s40279-014-0252-0.

16. Bompa T, Buzzichelli CA. Periodization Training for Sports. Champaign, IL: Human Kinetics 2015.

17. Yiannis Koutedakis, Harmel Huma, George Metsios, Alan Nevill, Giannis Giakas, Athanasios Jamurtas et al. The Effects of Three Months of Aerobic and Strength Training on Selected Performance and Fitness Related Parameters in Modern Dance Students, Journal of Strength and Conditioning Research 2007;21(3):808-812.

18. Bartholomew JB, Stults-Kolehmainen MA, Elrod CC, Todd JS. Strength gains after resistance training: the effect of stressful, negative life events, J Strength Cond Res 2008;22:1215-1221.

19. Roelants M, Delecluse C, Goris M, Verschueren S. Effects of 24 Weeks of Whole Body Vibration Training on Body composition and Muscle Strength in Untrained Females, International Journal of Sports Medicine 2004;25(1):1-5.

20. Ae-Rim Hong, Sang-Min Hong, Yun A Shin. Effects of Resistance training on Muscle Strength, Endurance, and Motor Unit According to Ciliary Neurotrophic Factor Polymorphism in Male College Students, J Sports Sci Med 2014;13(3):680-688.

21. Hickson RC. Interference of strength development by simultaneously training for strength and endurance. Eur. J Appl. Physiol 1980;45:255-263. 